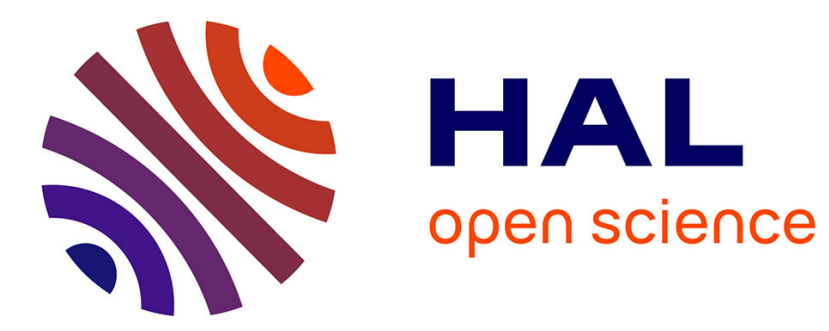

\title{
Impact behaviour of hollow sphere agglomerates with density gradient
}

Huabin Zeng, Stephane Pattofatto, Han Zhao, Yannick Girard, Valia Fascio

\section{To cite this version:}

Huabin Zeng, Stephane Pattofatto, Han Zhao, Yannick Girard, Valia Fascio. Impact behaviour of hollow sphere agglomerates with density gradient. 2009. hal-00443066

\section{HAL Id: hal-00443066 https://hal.science/hal-00443066}

Preprint submitted on 28 Dec 2009

HAL is a multi-disciplinary open access archive for the deposit and dissemination of scientific research documents, whether they are published or not. The documents may come from teaching and research institutions in France or abroad, or from public or private research centers.
L'archive ouverte pluridisciplinaire HAL, est destinée au dépôt et à la diffusion de documents scientifiques de niveau recherche, publiés ou non, émanant des établissements d'enseignement et de recherche français ou étrangers, des laboratoires publics ou privés. 


\title{
Impact behaviour of hollow sphere agglomerates with density gradient
}

\author{
H.B.Zeng ${ }^{\mathrm{a}}$, S.Pattofatto ${ }^{\mathrm{a}}$, H.Zhao ${ }^{\mathrm{a},{ }^{,}}$, Y.Girard ${ }^{\mathrm{b}}$ and V.Fascio ${ }^{\mathrm{c}}$ \\ ${ }^{a}$ Laboratoire de Mécanique et Technologie, \\ ENS Cachan/CNRS UMR8535/UPMC/PRES UniverSud Paris, \\ 61, Avenue du président wilson, 94235 Cachan cedex, \\ ${ }^{\mathrm{b}}$ EADS CCR, quai Marcel Dassault - BP 76 \\ 92152 Suresnes Cedex, France \\ ${ }^{c}$ ATECA/Advanced Materials \& Systems (AMS) Verlhaguet, \\ 82000 MONTAUBAN, France
}

\begin{abstract}
This paper presents a study on the influence of the density gradient profile on the mechanical response of graded polymeric hollow sphere agglomerates under impact loading. Quasi-static, standard split Hopkinson pressure bar (SHPB) tests as well as higher speed direct impact Hopkinson bar tests and Taylor tests are performed on such hollow sphere agglomerates with various density gradient profiles. It is found that the density gradient profile has a rather limited effect on the energy absorption capacity from those tests. It is because the testing velocity performed $(<50 \mathrm{~m} / \mathrm{s})$ is rather small with respect to its average sound wave speed (around $500 \mathrm{~m} / \mathrm{s}$ ) and the equilibrium stress state can be reached rather quickly. The high impact tests allow to generate a non-equilibrium state condition and the influence of density profiles is clearly observed. Besides, in order to extend this study to the situation beyond our testing limitations, a numerical model is built on the basis of the experimental behaviour data. It confirms the important influence of the density gradient profile under a non-equilibrium stress state situation. This study shows that placing the hardest layer as the first impacted layer and the weakest layer as the last layer has some benefits in terms of maximum energy absorption with a minimum force level transmitted to the protected structures.
\end{abstract}

Keywords : hollow spheres, SHPB, impact testing, cellular materials, energy absorption.

\section{Introduction}

Impact behaviour of cellular materials (honeycombs, foams, hollow sphere agglomerates, etc.) gain much scientific interest nowadays because of their worthy properties such as good specific resistances and high specific energy absorption capacities. For example, 
they can be employed as the core material of sandwich panels used to protect the cockpit against bird strikes or as the filling material in the hollow structures in a car to improve its energy absorption capacity [1-2].

Over the last decade, the idea of functionally graded materials (FGMs) was introduced in the materials sciences researches. The FGMs properties vary gradually within the material to optimize the global material function. Such FGMs structures can be easily found in nature. For example, bone possesses a gradient of densities in order to maximize the biological mechanical performance [3]. Nowadays, different manufacturing techniques have been explored to make artificial FGMs layers such as adhesive bonding, sintering, thermal spray, reactive infiltration, etc. [4-5]. FGMs properties have been thoroughly studied under quasistatic loading [6-8].

Important achievements have also been made in order to understand the mechanical response of FGMs submitted to stress waves and impact loading. A one-dimensional wave propagation model in FGMs is discussed by Bruck [9] to investigate the stress peak and the time delay in FGMs. Li et al. [10] have investigated the impulsive loading in the layered and graded structures using numerical models. They showed that the wave propagation consists of a complex coupling of elastic and viscoplastic part and the gradient profile plays an important role in the impact response. N.Gupta [11] has studied a functionally graded syntactic foam material (FGSF) and showed that a FGSF can support 60-75\% compression without any significant loss in strength or failure, and the gradient profile of FGSF can control the compressive modulus, strength, and total energy absorption. Apetre et al. [12] studied the low-velocity impact response of sandwich beams with functionally graded core. It is shown that the grading core reduces the maximum strains corresponding to the maximum impact load. All those works, even mostly based on the theoretical analyses and the numerical simulations, show that the introduction of property gradient will largely modify the overall response of the designed FGM structures.

The present paper is aimed at the understanding of the role played by the density gradient in the overall protective capacity of the foam-like cellular materials under impact loading. The studied model materials, described in the section 2, are polymeric hollow sphere agglomerates of the same apparent density but with various density gradient profiles. A quite complete experimental study, performed using quasi-static test, standard SHPB tests, direct impact Hopkinson bar tests as well as Taylor impact tests, will be shown in section 3. In the last section, a macroscopic numerical model is built and verified on the basis of experimental data. It allows for an extension of this study beyond our experimental limitation. 


\section{Mechanical behaviour of the hollow sphere agglomerates}

\subsection{Epoxy hollow spheres}

The studied hollow sphere agglomerates have been manufactured and supplied by ATECA. The replication process is used to produce polyepoxide hollow spheres of specified external diameter around $2.5 \mathrm{~mm}$. The thickness of hollow spheres is controlled in order to vary their density and the strength as a consequence.

Hollow sphere agglomerates can be made by bounding or sintering. Such hollow sphere agglomerates have not only good mechanical properties such as high specific energy absorption capacities and high specific strengths, but also excellent thermal and acoustic properties [13-14]. Previous studies in the open literature showed that the different packing of hollow spheres, for example body-centred cubic (BCC), face-centred cubic (FCC) and random packing, have different elastic modulus and initial yield strength [15-17]. However, the packing mode can not be analyzed in the present work because the supplied hollow sphere agglomerates are randomly packed and joined by sintering. It is noted that such a packing mode corresponds to the industrial mass production acquirement. Under such packing mode, the density of supplied agglomerates of four different hollow spheres is given in Table 1.

\begin{tabular}{|c|c|c|c|c|}
\hline Type name & C1 & C2 & C3 & C4 \\
\hline Density $\left(\mathrm{kg} / \mathrm{m}^{3}\right)$ & 156 & 242 & 343 & 468 \\
\hline
\end{tabular}

Table 1 Densities of the four types of hollow spheres

\subsection{Behaviour of randomly packed hollow sphere agglomerates of various densities}

Quasi-static and dynamic tests are performed to obtain the nominal stress-strain relation of those randomly packed hollow spheres agglomerates. The geometry of the specimen used is a cylinder of $40 \mathrm{~mm}$ height and $60 \mathrm{~mm}$ diameter. Such a choice of specimen size limited the eventual size effect (around 15 times cell (sphere) size).

Quasi-static tests were performed on a hydraulic machine at constant compression velocity. The tests were performed at a loading speed of $0.01 \mathrm{~mm} / \mathrm{s}$ that gives a nominal strain rate of $0.0025 / \mathrm{s}$. The results are quite repeatable and the hollow sphere agglomerates demonstrated a classic foam-like material behaviour (Figure 1). It is observed that there are three distinct phases: the linear elasticity, the plastic plateau and the densification regime. However, it is rather difficult to give an accurate value of Young's modulus and especially the plateau stress due to oscillations. Here the plateau stress is arbitrarily defined as average peak 
values in the early stage of plastic plateau regime. The identified Young's modulus and the plateau stress values as a function of the foam density are the following (Table 2):

\begin{tabular}{|c|c|c|c|c|}
\hline Type name & C1 & C2 & C3 & C4 \\
\hline Young's modulus (MPa) & 7 & 33 & 110 & 170 \\
\hline Plateau stress (MPa) & 0.8 & 2.2 & 4.1 & 7.1 \\
\hline
\end{tabular}

Table 2- Properties of four types of hollow spheres.

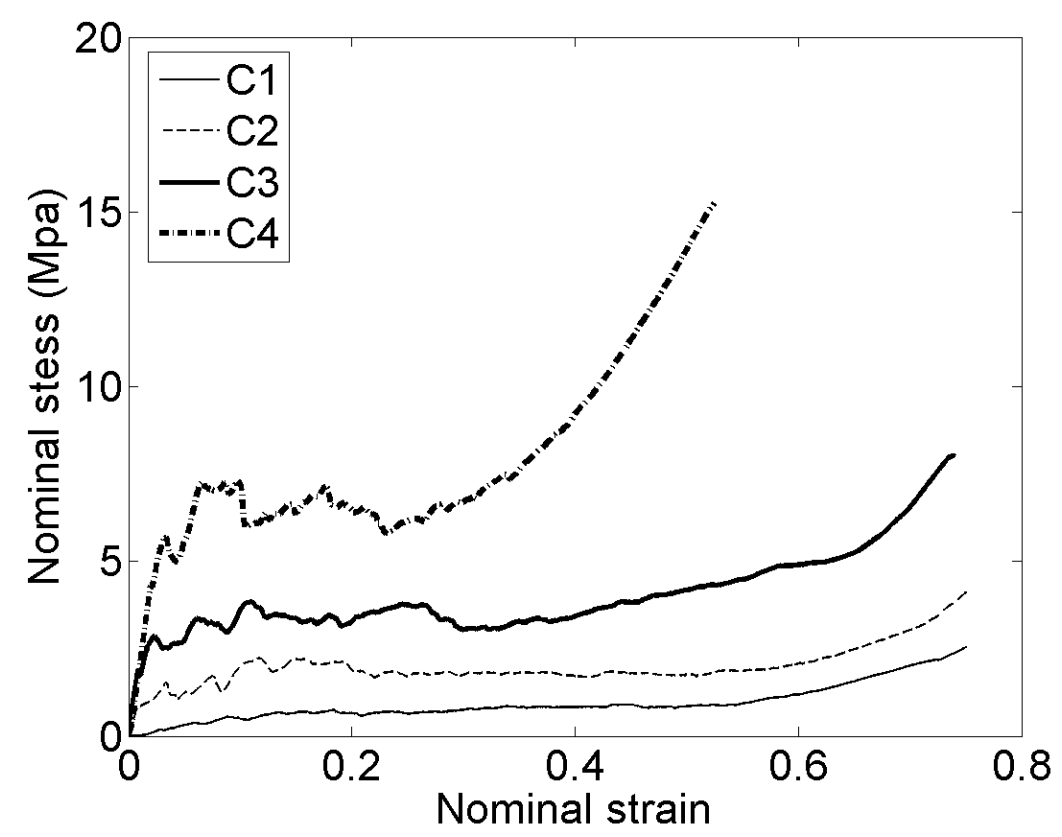

Figure 1 Quasi-static compressive behaviour of hollow sphere agglomerates (without density gradient)

Dynamic tests at low impact velocity were performed with a Split Hopkinson Pressure Bars (SHPB) apparatus which is a commonly used experimental technique to study the constitutive laws of materials at high strain rates [18]. The input and output bars (3 $\mathrm{m}$ long) are made from nylon material to ensure the impedance match [19]. The large diameter of the bars $(62 \mathrm{~mm})$ provides a correct representative specimen size compared to the size of the spheres. From SHPB test results, dynamic behaviour curves are plotted based on nominal quantities. Nominal stress is calculated as the measured output force divided by the initial cross-section of the specimen, as in the classical "2waves" method [19]. Nominal strain is the result of time integration of nominal strain rate. Strain rate is calculated as the relative measured velocity between output and input bar/specimen interfaces divided by the initial 
height of the specimen. Input and output force histories were checked and it validates the assumption of homogeneity in the specimen.

Figure 2 shows the results for dynamic compression tests at an impact speed of $21 \mathrm{~m} / \mathrm{s}$. The theoretical nominal strain rate is about $525 / \mathrm{s}$. The curves hardly show the densification regimes. It is due to the fact that the loading speed is not high enough to reach the densification regime within the $1.5 \mathrm{~ms}$ loading duration. The identified plateau stress values (defined as the peak value) as a function of the foam density are: $0.8 \mathrm{MPa}(\mathrm{C} 1), 2.9 \mathrm{MPa}(\mathrm{C} 2)$, 5.5 $\mathrm{MPa}(\mathrm{C} 3)$ and $8 \mathrm{MPa}(\mathrm{C} 4)$.

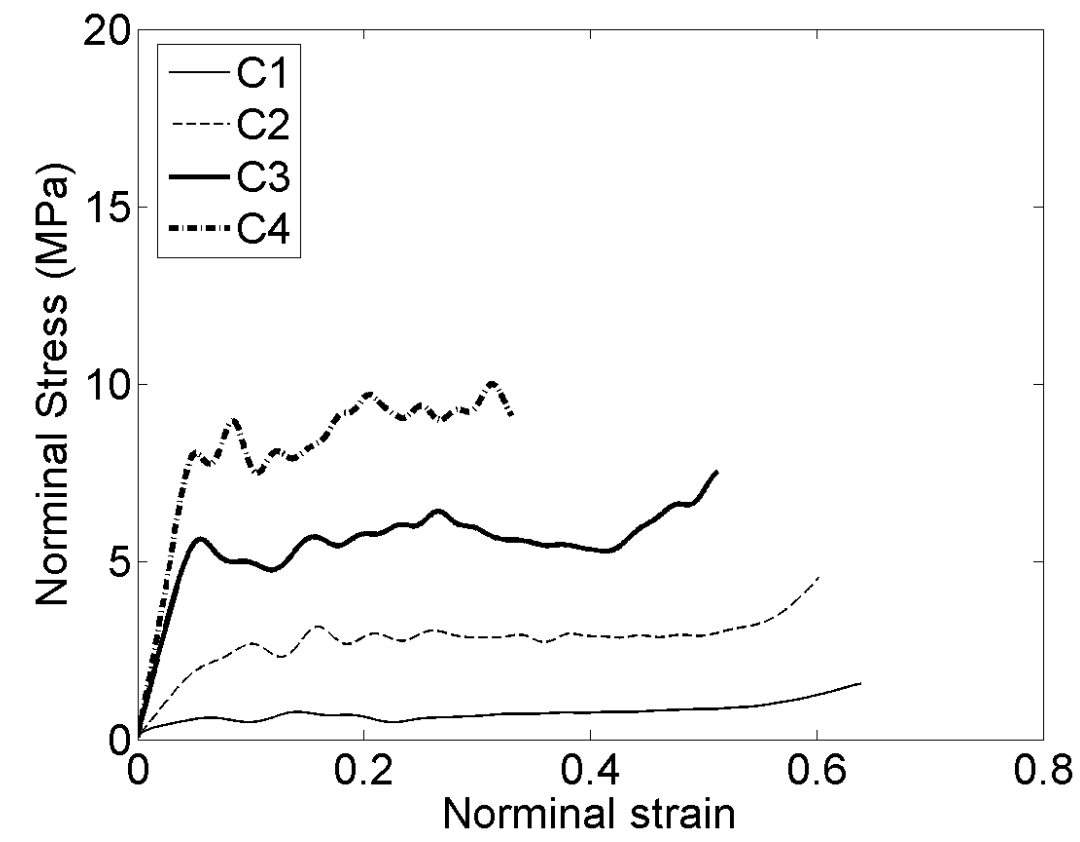

Figure 2 SHPB compressive testing results for hollow sphere agglomerates (without density gradient)

A comparison between static and dynamic plateau stresses is plotted in Figure 3. It shows that the studied materials have a rather small strain rate sensitivity of about $20 \%$. Such rate sensitivities should be derived from the viscosity of the base material [20]. The spheres are quite brittle and the failure mode of the agglomerate is a successive breaking of sphere layers. There is then no supplementary rate sensitivity due to the structural effect such as the inertia effect because spheres are typically considered as Type I structure [21-22]. 


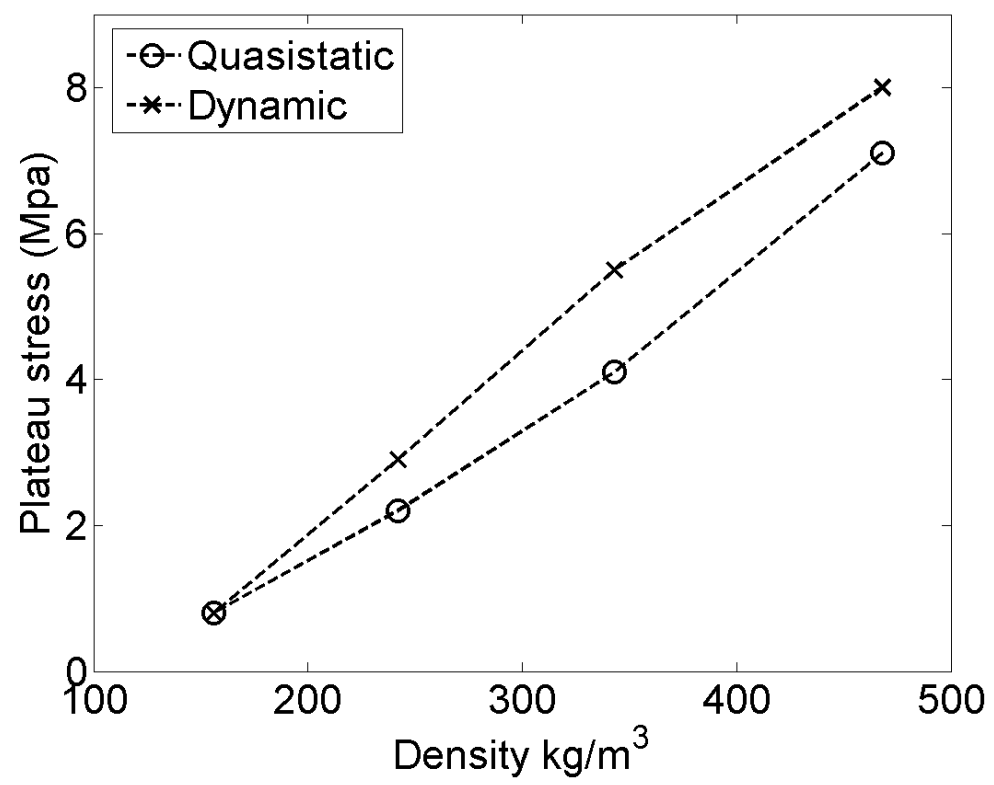

Figure 3 Strain rate sensitivity of hollow sphere agglomerates (without density gradient)

\section{Experimental study of the density graded hollow sphere structures}

\subsection{The studied gradient profile and specimens}

With four types of hollow spheres of different densities, graded agglomerates can be made with various gradient profiles. Indeed, there is a real interest to make such graded hollow sphere agglomerate because the strength/density profiles are controlled by the thickness of the spheres only. Therefore, the acoustic and thermal properties remain the same for any strength/density gradient profiles, which makes a real functionally selected profile possible.

Graded structures are built with four equal thickness layers of hollow spheres of four different densities $\mathrm{C} 1, \mathrm{C} 2, \mathrm{C} 3, \mathrm{C} 4$ investigated in the section 2 (table 1). Four gradient profiles named A4321 (B1234), D2431 and E4123 (Figure 4) are considered. The four numbers in this naming system denote the sequence of layer's density beginning from the impact face. A4321 (B1234) denotes then a linearly decreasing (increasing) graded structure. D2431 exhibits a gradient profile of an unbalanced inverse V-shape with less dense ends whereas E4123 has an unbalanced V-shape density profile with more dense ends. All the graded structures have the same apparent density of $300 \mathrm{~kg} / \mathrm{m}^{3}$. 

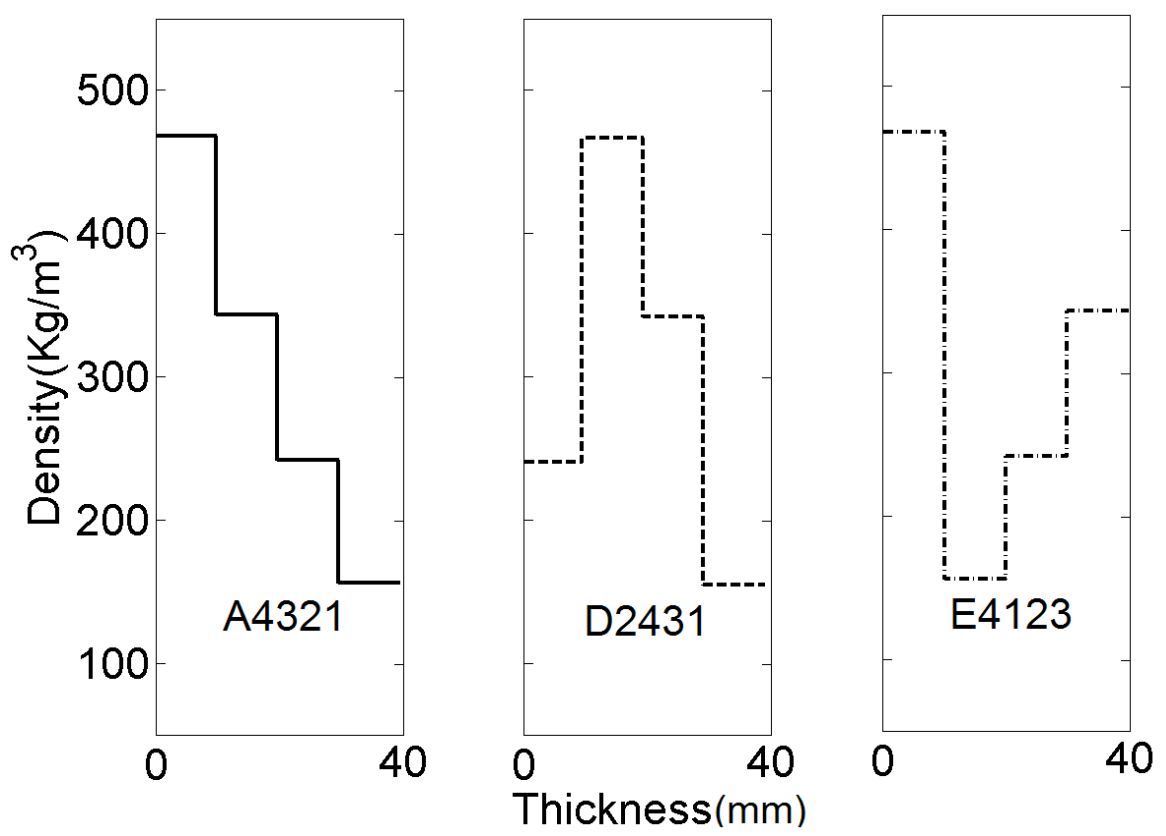

Figure 4 Density profile for the graded specimens: A4321, D2431 et E4123

The specimen of graded structures have the same geometry as before (40 $\mathrm{mm}$ high and $60 \mathrm{~mm}$ diameter). Each layer has a thickness of $10 \mathrm{~mm}$. Figure 5 shows schematically a specimen, randomly packed with a gradient profile of type A4321.

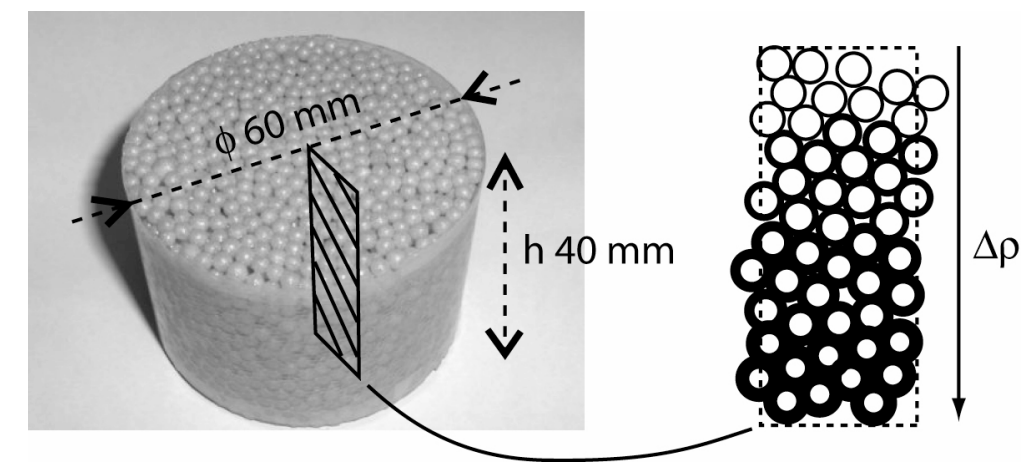

Figure 5 Geometrical parameters of the specimens

\subsection{Quasi-static and SHPB testing results}

The quasi-static compression tests on graded foams were performed at loading speed of $0.01 \mathrm{~mm} / \mathrm{s}$ that gives a nominal strain rate of $0.0025 / \mathrm{s}$. The nominal stress-strain curves of various gradient profiles are more or less the same (Figure 6a). The crushing should occur layer by layer from the weakest one to the strongest one. The four stress levels corresponding to the plateau stress of each layer $(\mathrm{C} 1, \mathrm{C} 2, \mathrm{C} 3, \mathrm{C} 4)$ can be clearly found $(0.8 \mathrm{MPa}, 2.2 \mathrm{MPa}$, 4.1 MPa and 7.1 MPa, plotted as straight lines in Figure 6a. 


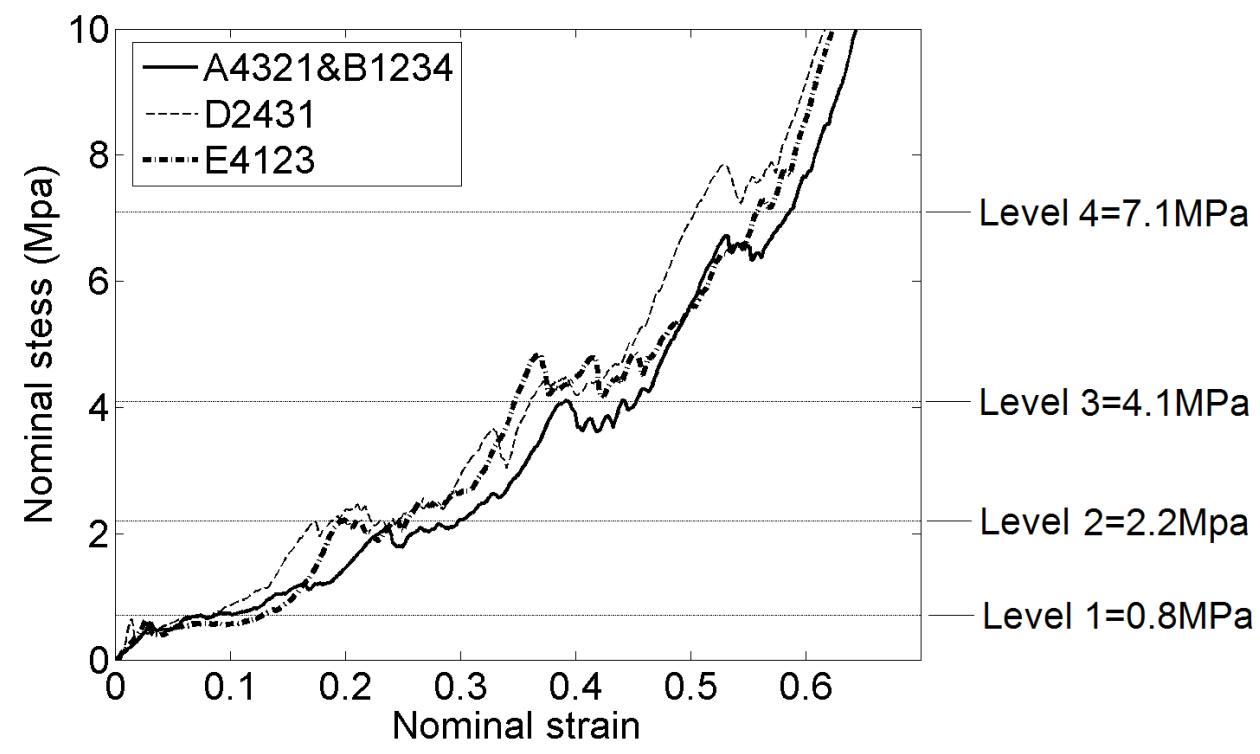

Figure 6a Graded structures under quasi-static compression tests

The standard SHPB tests (as described in the section 2) were made at an impact speed of $21 \mathrm{~m} / \mathrm{s}$. The same phenomenon as recorded in the quasi-static case is observed. There is no clear influence of the gradient profile and the four stress levels corresponding to the plateau stress in each layer can also be found (Figure 6b).

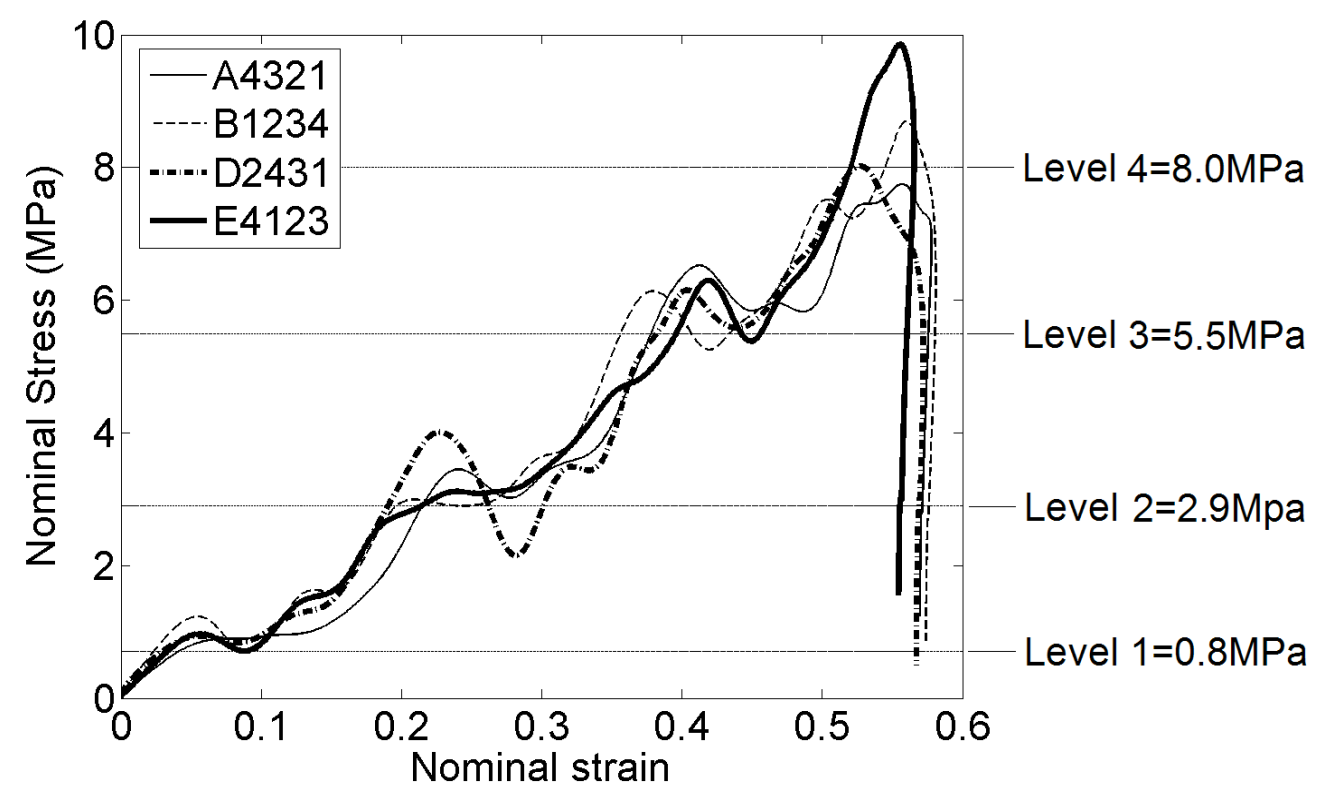

Figure $6 \mathrm{~b}$ Graded structures under SHPB tests at $21 \mathrm{~m} / \mathrm{s}$

Therefore, under standard SHPB testing conditions, the compression of the graded structure occurs as the successive compression of the layers, from least to most dense as in the quasi-static experiments. Indeed, the average sound speed in those graded structures is around $510 \mathrm{~m} / \mathrm{s}$ (average Young's modulus: $80 \mathrm{MPa}$, density $300 \mathrm{~kg} / \mathrm{m} 3$ ). An equilibrium 
state is established rather quickly with a specimen of $40 \mathrm{~mm}$ length. For instance, a round trip of elastic wave is around $156 \mu \mathrm{s}$ and the specimen is crushed by only $3,3 \mathrm{~mm}(8 \%$ nominal strain) during this period.

\subsection{Graded structures submitted to higher impact velocities}

Higher impact velocity testing is then desired. For this purpose, direct impact Hopkinson bar tests are performed using the $62 \mathrm{~mm}$ diameter and $6 \mathrm{~m}$ long Nylon Hopkinson bar and a shorter projectile (Figure 7a).

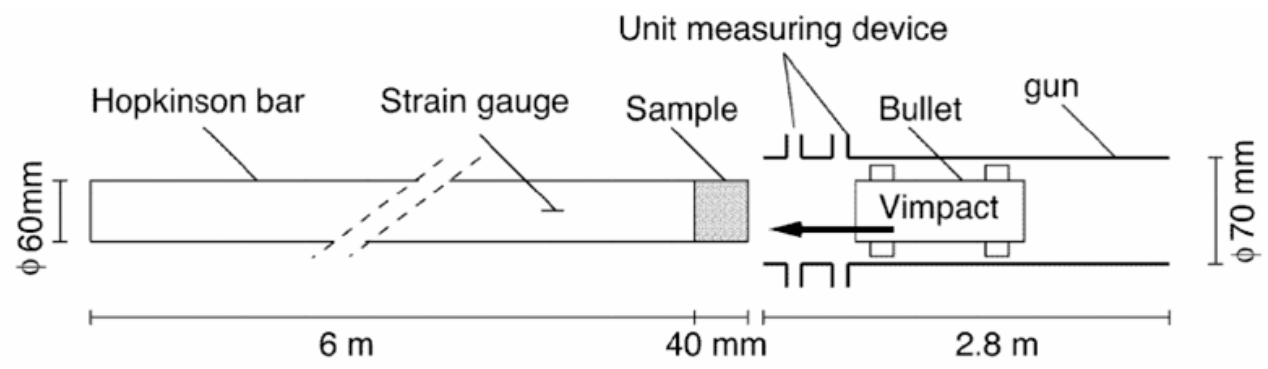

Figure 7a Direct impact Hopkinson bar test

The nominal stress is calculated by the force measured with the Hopkinson bar divided by the initial cross-sectional area. The nominal strain is evaluated with the following equations (1):

$$
\begin{aligned}
& v(t)=V_{0}-\int_{0}^{t} \frac{F(\tau)}{M} d \tau \\
& \varepsilon(t)=\frac{\int_{0}^{t}\left(v(\tau)-v_{b}(\tau)\right) d \tau}{L_{0}}
\end{aligned}
$$

where $v(t)$ denote the velocity time history of the projectile, $v_{0}$ the initial projectile velocity, and $F(t)$ the force measured by the Hopkinson bar. $M$ is the mass of the projectile and the specimen, $\mathrm{V}_{\mathrm{b}}(\mathrm{t})$ the velocity of the interface specimen/bar, and $\mathrm{L}_{0}$ the initial specimen length.

We note that the accuracy of strain given by eqn (1) depends on the equilibrium state of the specimen. It provides an acceptable accuracy for the plastic plateau regime. 
Additional tests like the Taylor impact test were also made, where the sample is cemented on the projectile so that the pressure bar measures the force on the impact side (Figure 7b).

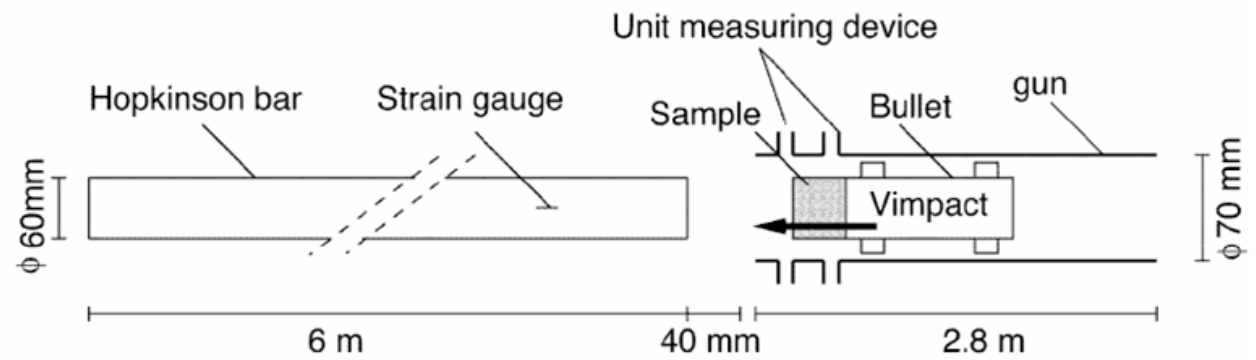

Figure $7 \mathrm{~b}$ Taylor test with Hopkinson bar

Such Taylor tests are aimed at investigating the forces of both sides of the sample, especially during the early stage of tests where the equilibrium state is not yet reached. Indeed, with a impact velocity of $41 \mathrm{~m} / \mathrm{s}$, if we take characteristic time of one round trip of $156 \mu \mathrm{s}$, the crushing distance is about $6.6 \mathrm{~mm}$ and namely $16 \%$ nominal strain.
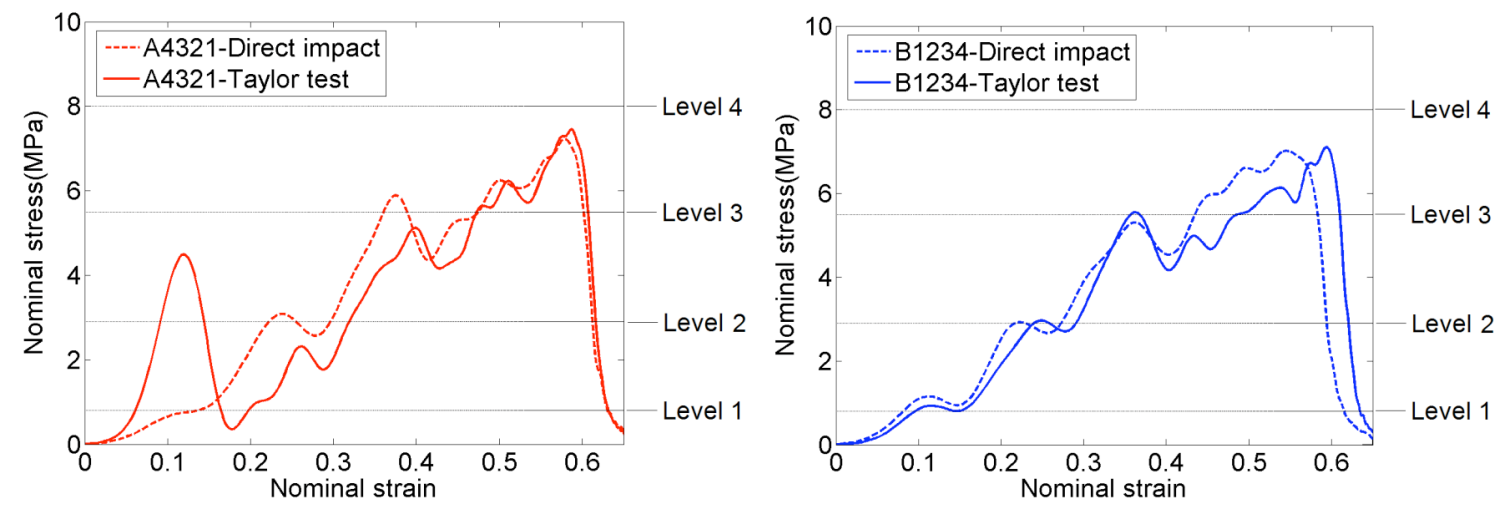

Figure 8 High velocity impact tests on A4321 and B1234

Figure 8 shows the forces measured from both sides of the sample with a linear gradient profile A4321(B1234). The four plateau stress levels as noted in the SHPB tests (figure $6 \mathrm{~b}$ ) can be also clearly found and it means that the test is still nearly under the equilibrium condition. However, if we focus on the early stage (say under 16\% strain, which corresponds roughly to one round trip of elastic wave), there is a big difference. There is a clear benefit to put the hardest layers in front of impacting mass (case A4321, figure 8, left) 
than the inverse (case B1234, figure 8, right). In the case A4321, more energy can be absorbed with a low level of the force transmitted to the rear face.

The same tendency is also observed for two other gradient profiles, where the difference exists only in the early stage of the test (Figure 9).
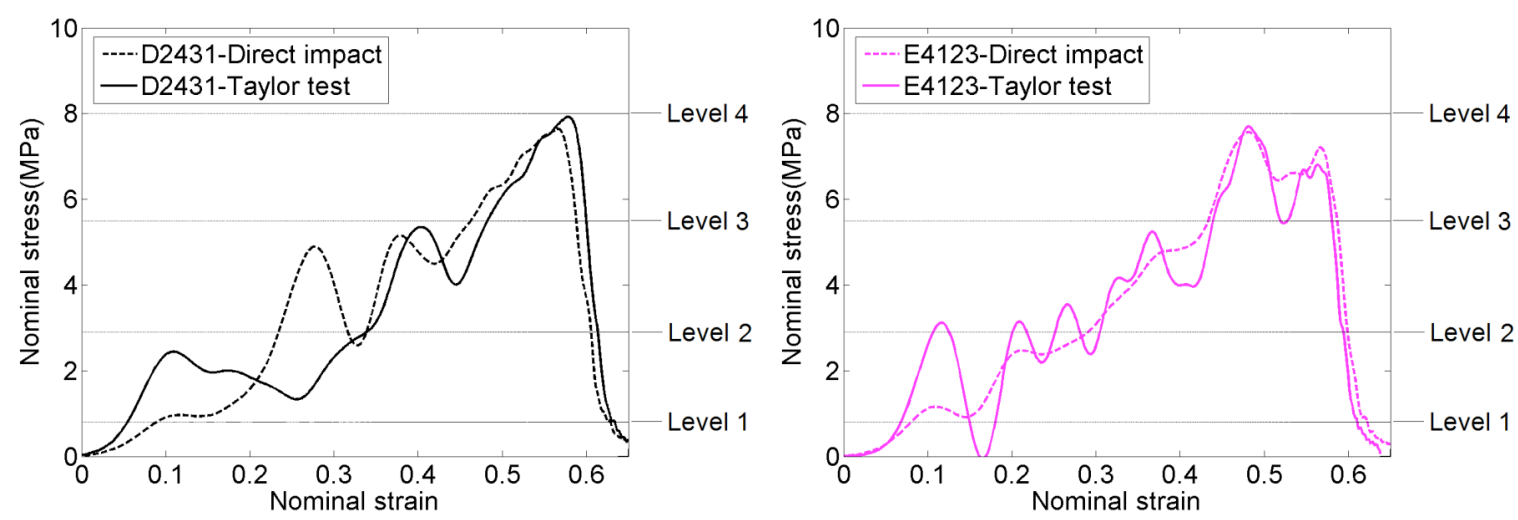

Figure 9 Higher speed impact tests on D2431 and E4123

\section{Numerical models of graded hollow sphere agglomerates}

The present testing methods can only create a non-equilibrium stress state in the early stage of the test. It provides a hint that gradient profile plays an important role in the energy absorption in this non-equilibrium stress state. Unfortunately, the testing velocity can not be high enough to provide a sufficient duration of this non-equilibrium state.

Numerical analysis is then proposed to broaden this study to cases that could not be performed on our present experimental devices. For this purpose, a numerical model of the studied graded hollow sphere structures is built.

\subsection{Macroscopic numerical model of graded hollow sphere agglomerates}

\subsubsection{Identification of the behaviour of each hollow sphere layers}

There is no difficulty in the geometrical modelling of these layered structures. The only question concerns the modelling of the behaviour of each layer. A macroscopic modelling is chosen for simplicity. The so-called "crushable foam" constitutive law, available in the Ls-Dyna code [23] is chosen to represent these hollow sphere agglomerates.

The parameters needed in the "crushable foam" material model are density $\rho$, Young's modulus E, Poisson's ratio and the hardening curve. The values of Young's modulus are those 
identified with quasi-static tests (Table 2). Poisson's ratio is set to zero because no significant lateral strain is observed during the tests.

The hardening curves for each layer are identified on the basis of experimental flow stress evolutions with respect to the volumetric strain $\varepsilon_{v}$. It is straight forward to derive the volumetric strain $\varepsilon_{\mathrm{v}}$ from nominal strain $\varepsilon_{\text {nominal }}$ measured during experiments given that the Poisson's ratio is set to zero :

$$
\varepsilon_{v}=1-\frac{V}{V_{0}}=1-\frac{L}{L_{0}}=\varepsilon_{\text {nominal }}
$$

where $V$ is the volume, $L$ the length, $V_{0}$ the initial volume and $L$ the initial length of an element.

Figure 10 shows the prescribed hardening curves vs volumetric strain, which is a smoothed approximation of experimental data shown in Figure 2.

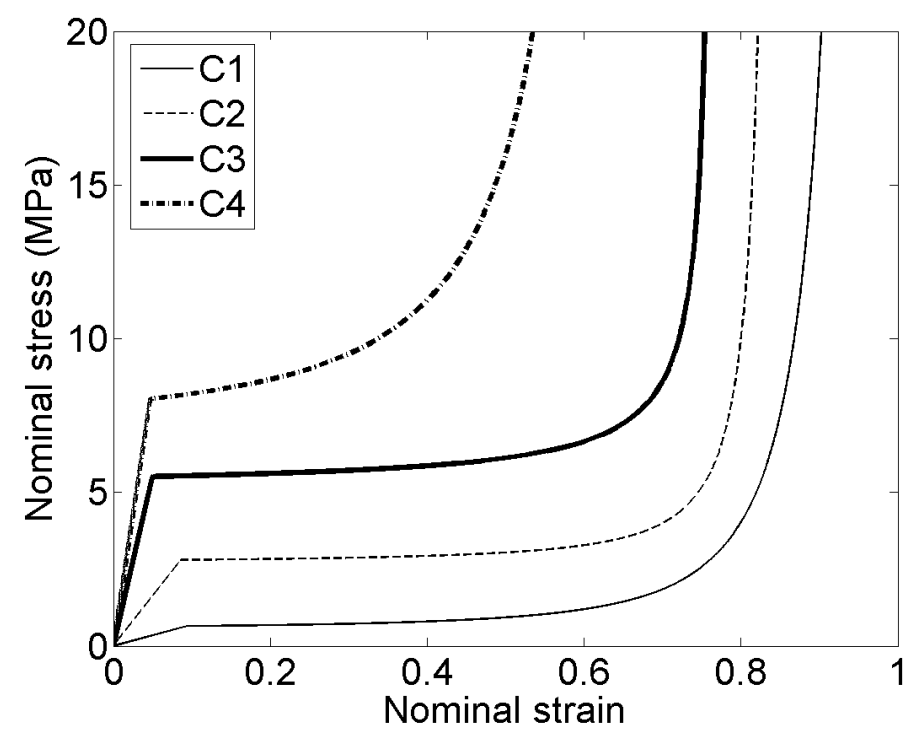

Figure 10 Prescribed flow stress-volumetric strain relation for the 4 hollow sphere agglomerates

\subsubsection{Validation of the numerical model of graded hollow sphere agglomerates}

In order to validate such a rather rough macroscopic numerical model, the SHPB tests as well as high velocity impact tests are all simulated. The specimen geometry is designed as a cylinder of $40 \mathrm{~mm}$ high and $60 \mathrm{~mm}$ diameter as the real tested specimens. It is assumed that the four graded foams are made of four layers with a layer thickness of $10 \mathrm{~mm}$. Each layer is meshed with 20 elements in the height. A mesh of 8-node 3D solid elements with one-point integration is used in the simulations. 
To apply the boundary conditions, it is supposed that the graded structures are placed between two rigid and mobile walls (Figure 11a). The velocities prescribed to both walls are those measured during SHPB experiments by the input and the output bars, or those obtained in high impact velocity tests. Figure $11 \mathrm{~b}$ shows an example of prescribed velocities respectively on the input and output rigid walls.

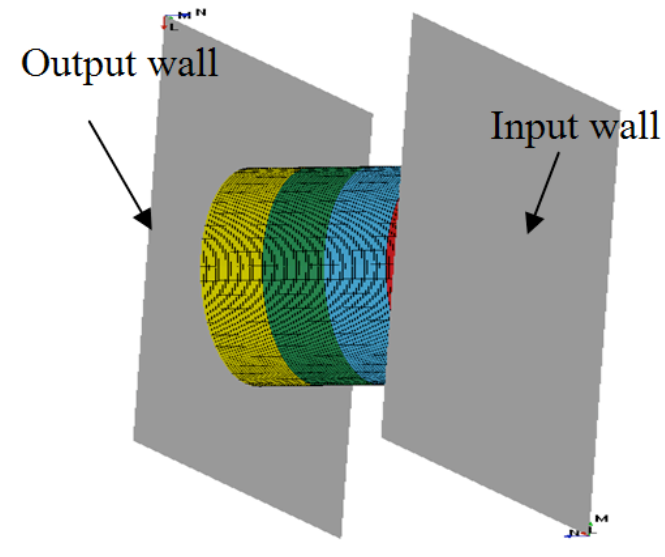

(a)

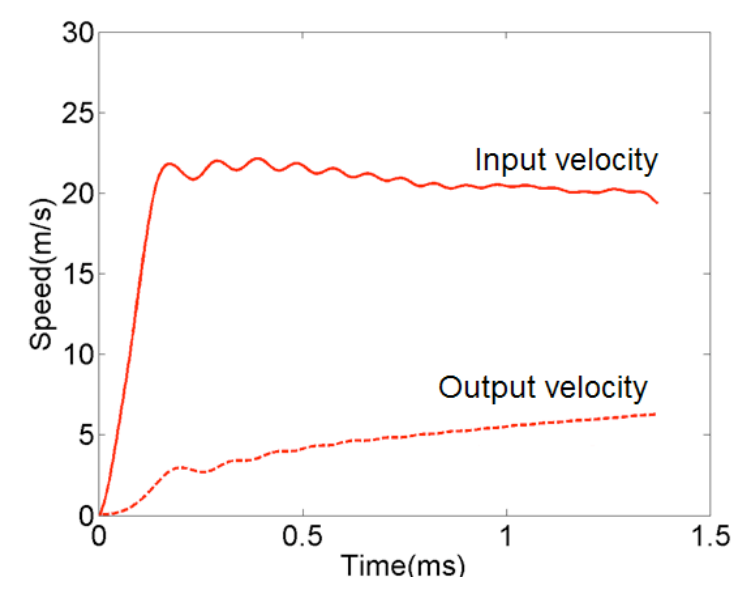

(b)

Figure 11 (a) Scheme of the boundary conditions (b) Prescribed velocity time history

The validity of the presented numerical model is estimated by a comparison between the experimental and the numerical forces curves. Figure 12 illustrates the experimentsimulation comparisons of standard SHPB tests at $21 \mathrm{~m} / \mathrm{s}$. Figure 12a plots the time history of force (divided by the cross-sectional area) for the gradient profile A4321 whereas Figure 12b is for the gradient profile B1234. The simulation of two other gradient profiles (D2431 and E4123) gives similar results. Therefore, the present macroscopic numerical model is able to capture the compression history observed during the SHPB experiments.

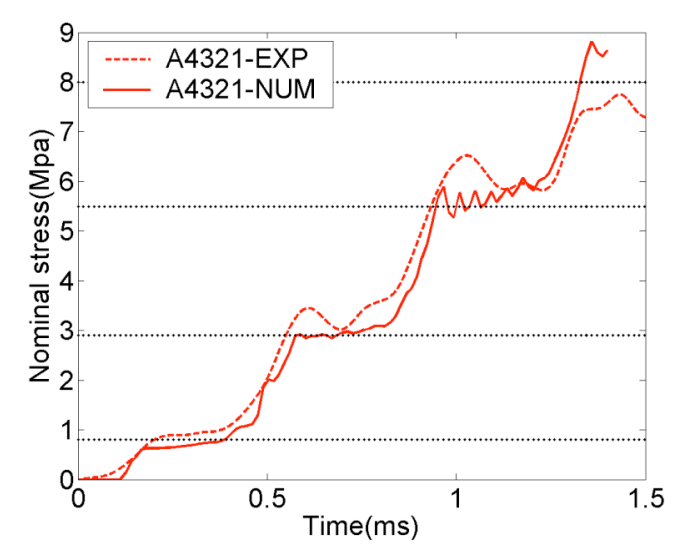

(a)

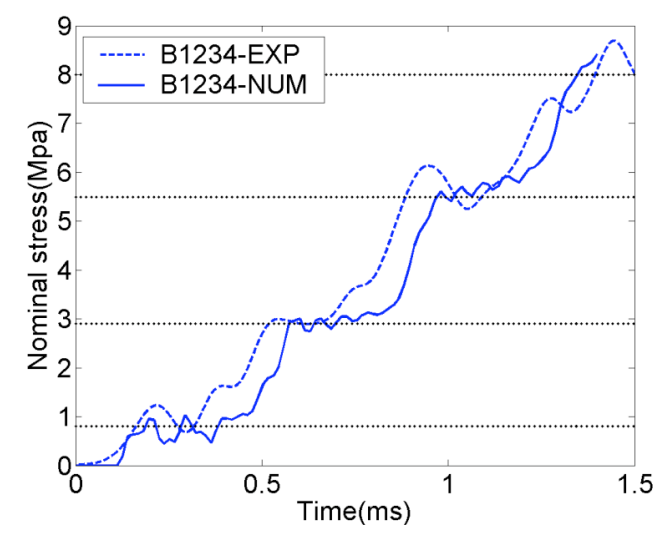

(b) 
Figure 12 The numerical and experimental comparison at 21m/s a) A4321, b) B1234

For higher impact velocity tests (at $41 \mathrm{~m} / \mathrm{s}$ ), the comparisons of experimental and simulated forces at both sides of the samples are shown because of the non-equilibrium state at early stage. Figure $13 \mathrm{a}$ and $\mathrm{b}$ plots respectively comparisons for the gradient profiles A4321 and B1234. The numerical model can once again capture the essential features of the experiments, especially the non-equilibrium state at the early testing stage for the gradient profile A4321 where the force peak at impact side around $0.1 \mathrm{~ms}$ is well simulated. It is also noted that such force peak does not exist in the simulation for the gradient profile B1234, as it has been observed in the experiment.
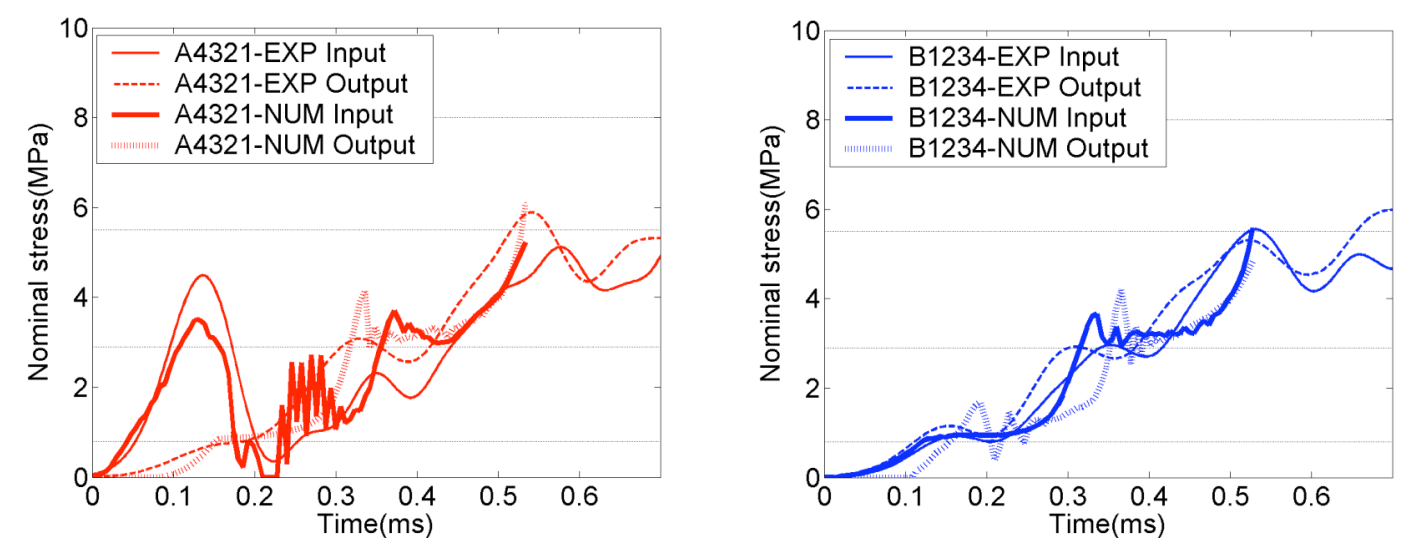

Figure 13 The numerical and experimental comparison at 41m/s left) A4321, right) B1234

The simulations of two other gradient profiles are also in good agreement with the experiments. It can be concluded that the numerical model used are able to provide reliable results to dynamic impacts on those graded hollow sphere structures wherever there is or not an equilibrium state during impact. Such numerical tool can be then used to extend the above experimental studies of the gradient profile influence on the behaviour of the graded hollow sphere structures.

\subsection{Numerical study of the influence of density gradient profiles}

\subsubsection{Graded hollow sphere structures with a force-free rear face}

First of all, a more or less academic case is considered where a specimen not supported and initially at rest is impacted by a rigid wall at $41 \mathrm{~m} / \mathrm{s}$ (Figure 14). It is an equivalent case of impact against a immobile rigid wall of a specimen launched at $41 \mathrm{~m} / \mathrm{s}$. It is also an idealized model of the impact of a small projectile in the centre of a sandwich panel 
with foam-like material core only supported at the boundary. Such a case is chosen because of its evident non-equilibrium state during the whole impact duration (rear face stress is always zero). The same impact velocity of $41 \mathrm{~m} / \mathrm{s}$ as in the case of the successfully simulated test allows to stay within the valid range of our numerical model.

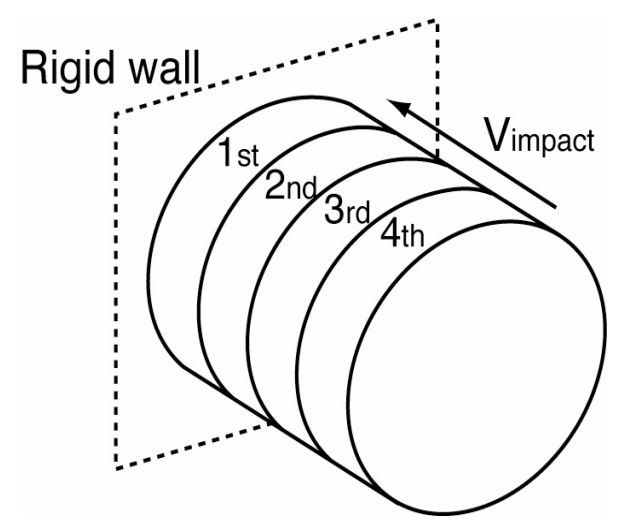

Figure 14- Impact of graded foam against a rigid wall

Impacts at $41 \mathrm{~m} / \mathrm{s}$ are then simulated for the four studied gradient profiles: (a) A4321, (b) B1234, (c) D2431 and (d) E4123. Stress time histories at the interface impact wall/sample and at the middle of the each layers of the graded structure are extracted to illustrate the different reactions due to the gradient profiles.

Figure 15 depicts the simulated five nominal stress-time histories with respect to global nominal strain. It is clearly observed that the response depends strongly on the gradient profiles of the graded hollow sphere structures. The two main features can be summarized as follows: 


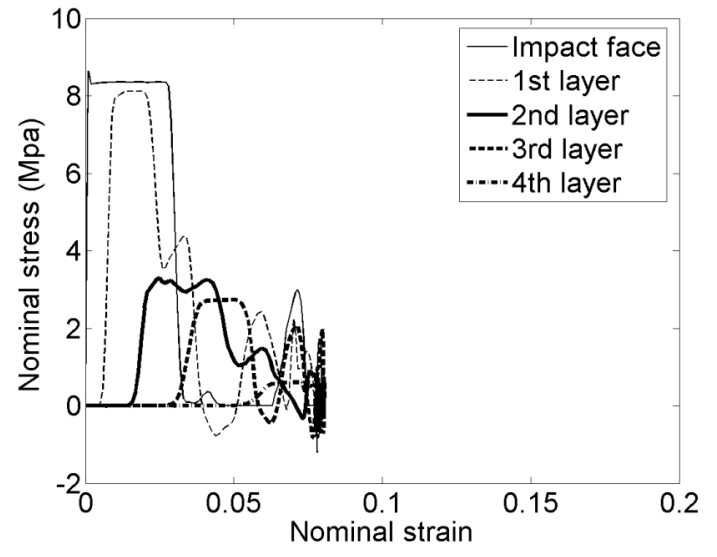

(a) A4321

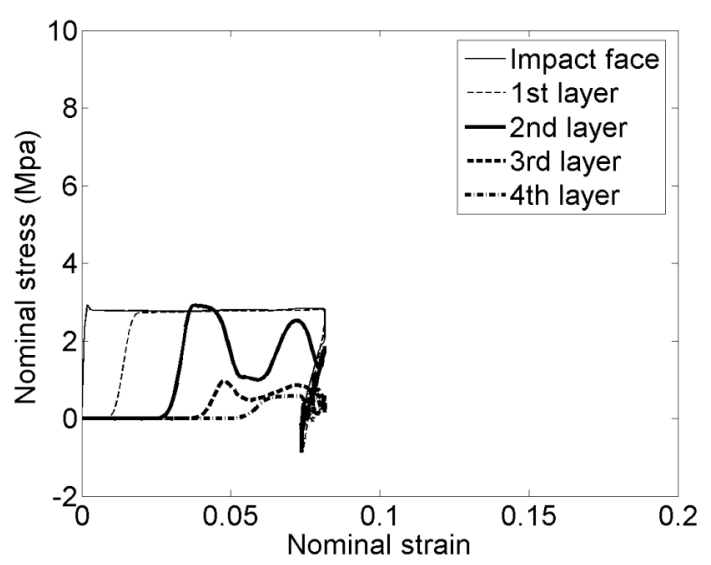

(c) D2431

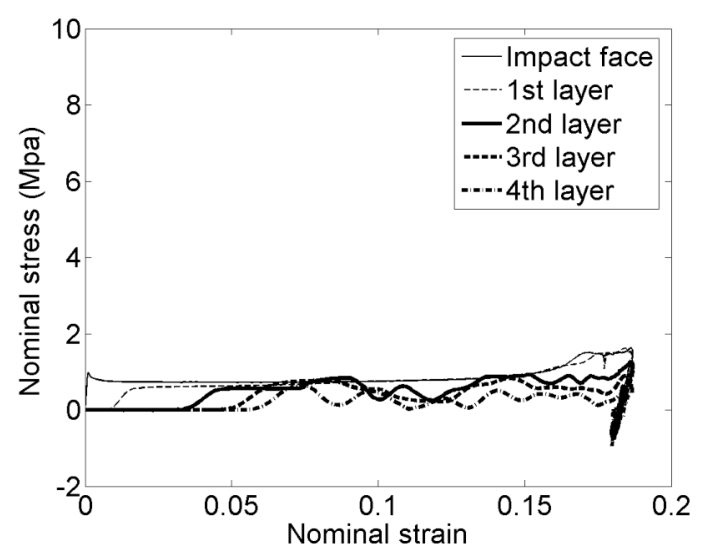

(b) B1234

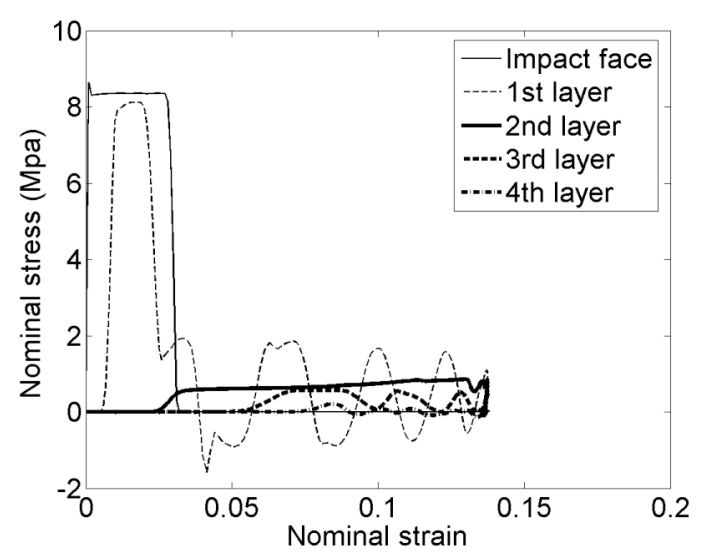

(d) E4123

Figure 15 Stress in the interface and in the middle of each layer for a) A4321, b) B1234, c)

$$
\text { D2431, d) E4123 }
$$

i) The force at the impacting interface depends mostly on the first layer strength. The case (a) A4321 and (d) E4123 possess the same $8 \mathrm{MPa}$ stress magnitude on the impacting interface corresponding to the plateau stress of the 1st and hardest layer, whereas the case (b) $\mathrm{B} 1234$, the stress at the interface is much smaller (only $1 \mathrm{MPa}$, roughly the plateau force of the weakest layer placed as the first layer).

ii) The total final strain depends on the crushing level of "weakest" layer. The final strain is much smaller when the "weakest" layer is placed at the free end as it is the case (a) A4321 and (c) D2431. Besides, a V-shape density gradient seems to have a large final strain. Indeed, the case (a) A4321 undergoes a final strain which is a half of the case (d) E4123, even if the stress at the impacting interface is the same. 
From this simulation, it could be concluded that the gradient profile have a strong influence on the impacting force amplitude as well as total final strain of the graded hollow spheres agglomerates in a non-equilibrium stress state. It indicates that the density gradient profile can be used to design the best energy absorption capacity of such structure with respect to a given loading condition.

\subsubsection{Graded hollow sphere structures impacted at $200 \mathrm{~m} / \mathrm{s}$}

A more industrially realistic case is considered in the following. The samples of the four density gradient profiles are crushed between the two rigid walls as in the section 4.1.2. Here, the output side is a fixed wall whereas the input side is moving wall at a prescribed velocity of $200 \mathrm{~m} / \mathrm{s}$. Such configuration is similar to the real situation where a foam-like material is used to absorb impact energy and to protect the structure behind it. The reaction forces of the rigid walls for the four cases are shown in Figure 16.

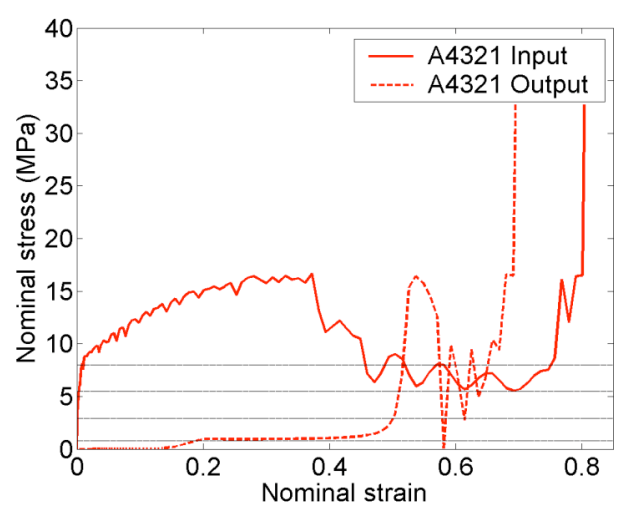

a) A4321

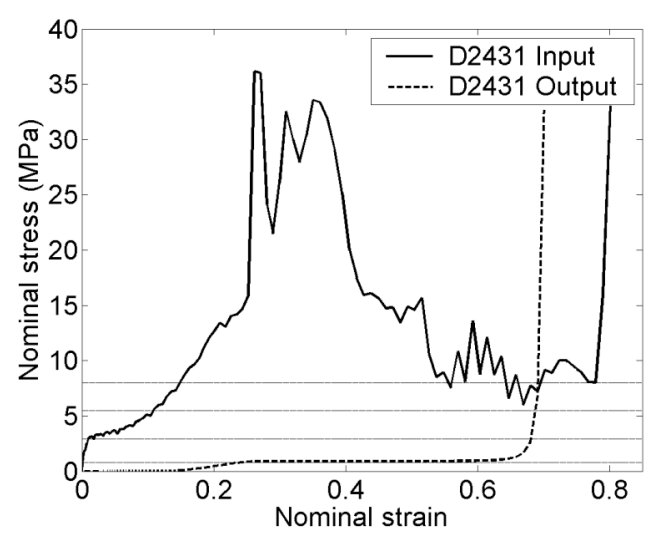

c) D2431

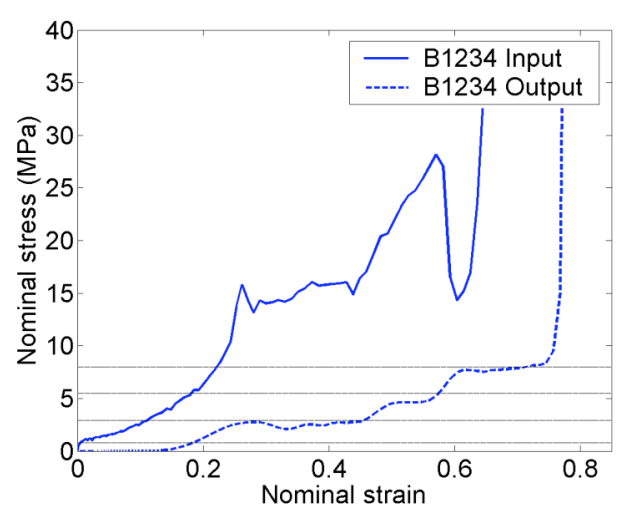

b)B1234

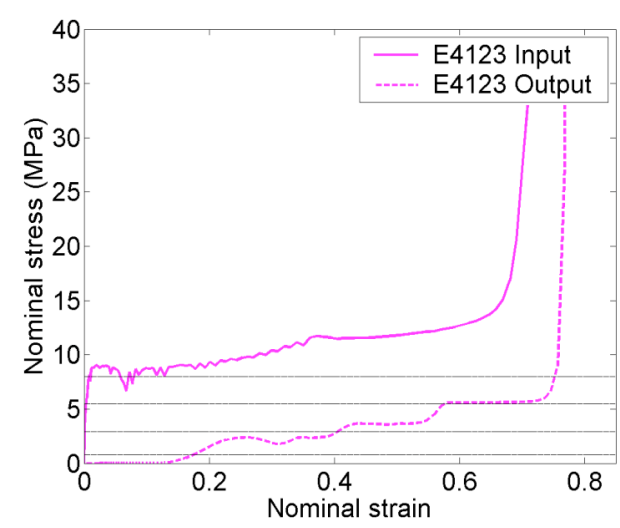

d) E4123

Figure 16 Nominal stresses at input/output sides in simulated tests at $200 \mathrm{~m} / \mathrm{s}$ for the four density gradient profile. 
Under such impact condition, the equilibrium state has never been reached and the density gradient profile does play an important role because the input and output forces for the four cases are all different (Figure 16). However, it is difficult to compare quantitatively the difference from each other. It is noticed that input side nominal stress reaches values much higher than the plateau values of the "hardest" layer $(8 \mathrm{MPa})$ and this indicates that the densification regime is reached. Thus, possible shock front can exist within layers which make relevant analysis more complicated [24-25]. One may also notice that if the "weakest" layer is placed at the output side as the cases A4321 (fig. 16a) and D2431 (fig. 16c), the output force is limited by the plateau force in the "weakest" layer. It means that placing the "weakest" layer at the output side will reduce the force transmitted to the protected structure.

In order to provide a clearer trend of the role played by the density gradient in terms of energy absorption efficiency, an efficiency diagram showing the evolution of absorbed energy as a function of the force transmitted to the protected structure.

Figure 17 depicts such an efficiency diagram for simulated tests on the four graded hollow structures. The most efficient gradient profile should be the one that remains located at the top-left corner of the diagram. This efficiency indicator confirms that placing the "weakest" layer in contact with the protected structure should be a winning strategy as it is the case for A4321 and D2431.

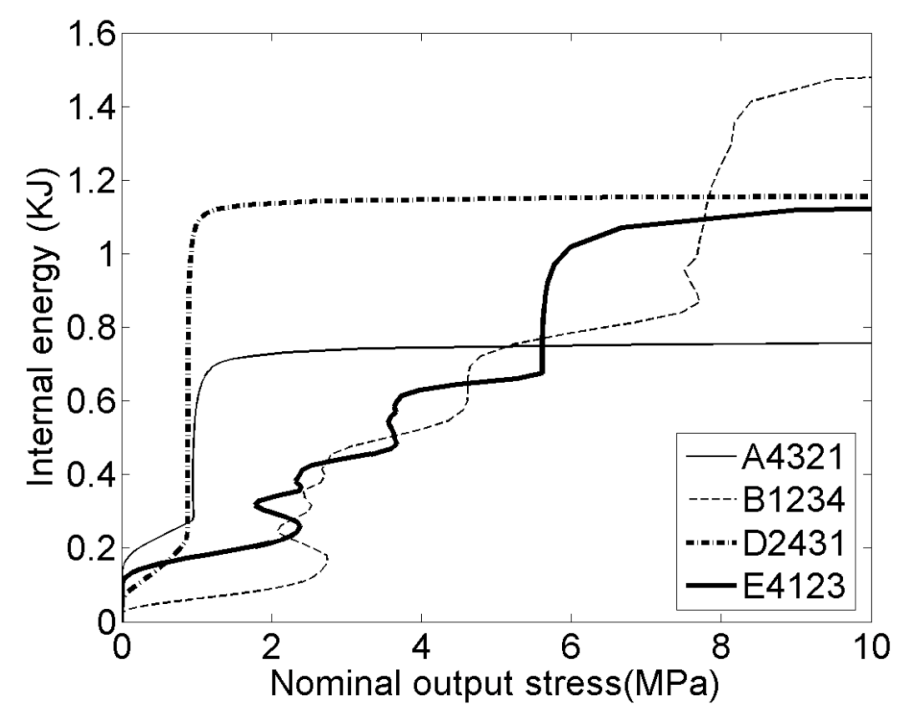

Figure 17 Efficiency diagram for the four graded hollow sphere agglomerates

As a conclusion, in the case of very high impact velocities, there is a clear influence of the gradient profile on the mechanical response of the graded hollow sphere structures, in terms 
of two parameters defining the efficiency of the protection: the output stress and the absorbed energy.

\section{Conclusion}

In this paper, the influence of density/strength gradient on the impact behaviour of functionally graded cellular materials has been studied. The materials investigated are the graded hollow sphere agglomerates with polymeric hollow spheres of different densities.

Experimental studies are performed under quasi-static loading, standard SHPB test $(21 \mathrm{~m} / \mathrm{s})$ as well as direct impact loading $(41 \mathrm{~m} / \mathrm{s})$. On the one hand, it confirms that there is no significant influence of gradient profile when an equilibrium state is quickly reached as in the case of SHPB tests (small time delay for a round trip of elastic wave due to high average wave speed in our specimen). On the other hand, the gradient profile plays an important role in both the energy absorption and the transmitted force when the equilibrium state is not reach as in the case of the early stage of direct impact tests.

In order to extend this study beyond experimental limitations, a macroscopic numeric model is built, with constitutive laws calibrated using experimental data on the hollow sphere agglomerates of different densities. Such a model is proved to be valid because the simulation data is in good agreement with available testing results on the graded hollow sphere agglomerates. With this numerical model, numerical virtual tests beyond our experimental limitations are made. It turns out that a winning strategy in term of more absorbed energy with a low transmitted force could consist of placing the "hardest" layer as the first impacted layer and the "weakest" layer in contact with the protected structure to reduce the transmitted force.

\section{Acknowledgement}

The authors recognize and acknowledge the European network of Excellence, KMMNoE, for the financial support of the presented work.

\section{Reference}

[1] Gibson L.J., and Ashby M., Cellular solids. Pergamon Press, 1988.

[2] Zhao H., Cellular materials under impact loading. IFTR-AMAS Edition, Warsaw, Poland. ISSN 1642-0578, 2004. 
[3] Daxner T., Rammerstorfer F.G. and Böhm H.J., Adaptation of Density Distributions for Optimising Aluminium Foam Structures, Material Science \& Technology 16 (2000), 935939.

[4] Suresh S, Mortensen A. Fundamentals of functionally graded materials: Processing and thermomechanical behaviour of graded metals and metal-ceramic composites. London: IOM Communications Ltd; 1998.

[5] Miyamoto Y., Kaysser W.A., Rabin B.H., Kawasaki A. and Ford RG, Functionally graded materials: Design, processing and applications. Boston: Kluwer Academic Publishers; 1999.

[6] Suresh S., Giannakopoulos A.E. and Alcala J., Spherical indentation of compositionally graded materials: theory and experiment. Acta Mater. 45 (1997), 1307-1321.

[7] Suresh S., Mortensen A., 1998. Fundamentals of Functionally Graded Materials. The Institute of Materials, London.

[8] Suresh S., Graded materials for resistance to contact deformation and damage. Science 292 (2001), 2247-2251.

[9] Bruck H.A., A one-dimensional model for designing functionally graded materials to manage stress waves. International Journal of Solids and Structures 37 (2000), 6383-6395.

[10] Li T., Ramesh K.T. and Chin E.S.C, Dynamic characterization of layered and graded structures under impulsive loading. International Journal of Solids and structures 38 (2001), 6045-6061.

[11] Gupta N., A functionally graded syntactic foam material for high energy absorption under compression. Materials Letters 61 (2007), 979-982.

[12] Apetre N.A., Sankar B.V., and Ambur D.R., Low-velocity impact response of sandwich beams with functionally graded core. International Journal of Solids and Structures 43 (2006), 2479-2496.

[13] Queheillalt D.T., Sypeck D.J., and. Wadley H.N.G, Ultrasonic characterization of cellular metal structures. Materials Science and Engineering C323 (2002) 138-147.

[14] Sanders W.S., Gibson L.J., Mechanics of hollow sphere foams. Materials Science and Engineering C347 (2003), 70-85.

[15] Sanders W.S., Gibson L.J., Mechanics of BCC and FCC hollow-sphere foams. Materials Science and Engineering C352 (2003), 150-161.

[16] Lim T.J., Smith B., and McDowell D.L., Behavior of a random hollow sphere metal foam. Acta Materialia 50 (2002), 2867-2879. 
[17] Gao Z.Y., Yu T.X., and Zhao H., Mechanical behavior of metallic hollow sphere (MHS) materials: An experimental study, ASCE Journal of Aerospace Engineering 21(2008), 206-216.

[18] Zhao H., Experimental characterisation of materials behaviour under dynamic loading, Computer \& structures 81(2003), 1301-1310.

[19] Gary G., Klepaczko J.R, Zhao H., Correction de dispersion pour l'analyse des petites déformations aux barres de Hopkinson, Journal of Physique 1 (1991), C1, 403-410.

[20] Zhao H., Elnasri I., Abdennadher S., An experimental study on the behaviour under impact loading of metallic cellular materials. International Journal of Mechanical Sciences 47 (2005), 757-774.

[21] Gao Z.Y, Yu TX, and Lu G., A study on type II structure. Part I: a modified one dimensional-spring model. International journal of impact engineering 31 (2005), 895-910.

[22] Zhao H., and Abdennadher S., On the strength enhancement under impact loading of square tubes made from rate insensitive metals. International Journal of Solids and Structures 41 (2004), 6677-6697.

[23] Hallquist J.O., Ls-Dyna theoretical manual. Livermore Software Technology Corporation, 1998.

[24] Elnasri I., Pattofatto S., Zhao H., Tsitsiris H., Hild F. and Girard Y., Shock enhancement of cellular structures under impact loading: Part I Experiments. Journal of the Mechanics and Physics of Solids 55 (2007), 2652-2671.

[25] Pattofatto S., Elnasri I., Zhao H., Tsitsiris H., Hild F. and Girard Y., Shock enhancement of cellular structures under impact loading: Part II Analysis, Journal of the Mechanics and Physics of Solids 55 (2007), 2672-2686. 